Научная статья

УДК 130.2

DOI: $10.17213 / 2075-2067-2021-6-237-245$

\title{
СОЦИОКУЛЬТУРНОЕ ПРОСТРАНСТВО СОВРЕМЕННОГО ОБЩЕСТВА: ГЕНЕЗИС И ОСНОВНЫЕ ХАРАКТЕРИСТИКИ
}

\author{
Василий Сергеевич Любченко
}

Южно-Российский государственный политехнический университет (НПИ) имени М. И. Платова, Новочеркасск, Россия

v.s.lyubchenko@gmail.com, ОRСID:0000-00010583302479, AuthorID РИНЦ: 372408

Аннотация. Цель исследования - определение основных параметров сочиокультурного пространства современного общества, выделение в нем структурных элементов и анализ характера их взаимодействия.

Методология. Используется сочиокультурный подход, согласно которому общество необходимо рассматривать как единство культурного и сочиального, а также методология идеальных типов М. Вебера, позволяющая исследовать сочиум на уровне действующих субъектов.

Результаты исследования. Определены основные характеристики социокультурного пространства современного общества, или общества модерна, его генезис и современное состояние. Выделены основные взаимодействующие в нем изенностные системы, тенденичии их изменения.

Перспективы исследования. Исследование соииокультурного пространства общества модерна позволяет провести содержательный анализ его трансформации в постмодерн и выявить направления его дальнейтего развития.

Ключевые слова: общество модерна, сочиокультурное пространство, сочиальная группа, ценности, мотивы поведения

Для цитирования: Любченко В.С. Сочиокультурное пространство современного общества: генезис и основные характеристики // Вестник Южно-Российского государственного технического университета. Серия: Социально-экономические науки. 2021. T. 14, № 6. C. 237-245. http://dx.doi.org/10.17213/2075-2067-2021-6-237-245.

Original article

\section{SOCIO-CULTURAL SPACE OF MODERN SOCIETY: GENESIS AND MAIN CHARACTERISTICS}

\author{
Vasiliy S. Lyubchenko
}

Platov South Russian State Polytechnic University (NPI), Novocherkassk, Russia v.s.lyubchenko@gmail.com, ORCID:0000-00010583302479, AuthorID RSCI: 372408

\footnotetext{
Abstract. The purpose of the study is to determine the main parameters of the socio-cultural space of modern society, to identify structural elements in it and to analyze the nature of their interaction.

(C) Любченко В.С., 2021
} 
Methodology. The sociocultural approach is used, according to which society should be considered as a unity of cultural and social, as well as the methodology of M. Weber's ideal types, which allows to study society at the level of actors.

The results of the study. The main characteristics of the socio-cultural space of modern society, or modern society, its genesis and current state are determined. The main value systems interacting in it and the trends of their changes are highlighted.

Research prospects. The study of the socio-cultural space of the modern society allows for a meaningful analysis of its transformation into postmodern and to identify the directions of its further development.

Keywords: modern society, socio-cultural space, social group, values, motives of behavior

For citation: Lyubchenko V.S. Socio-cultural space of modern society: genesis and main characteristics // Bulletin of the South Russian State Technical University. Series: Socio-economic Sciences. 2021; 14(6): 237-245. (In Russ.). http://dx.doi.org/10.17213/2075-2067-2021-6-237-245.

Введение. Мы будем исходить из того, что социокультурное пространство - это единство социального и культурного. М. Вебер в своих работах убедительно показал, что в исследовании социума нельзя ограничиваться рассмотрением его социальной структуры, экономической, политической и духовной сфер, выделяя их обобщенные характеристики и свойственные им закономерности развития, например, исследовать изменения в политической сфере западноевропейского общества в послевоенное время или развитие экономики за тот же период, изменения социальной структуры и т.д. В целом такие исследования правомерны и необходимы. Однако они, как правило, не переходят на уровень действующих субъектов, индивидов и социальных групп, их ценностей, целей, мотивов поведения.

Заслуга М. Вебера, как известно, в том, что он выделил в качестве объекта исследования социального знания действующих индивидов, мотивы их действий, которые и создают конкретное общество, его экономику, политику, социальные институты и т.д. [1]. Если рассматривать конкретное общество в динамике, процессуально, то мы неизбежно должны исследовать его «субъективную» составляющую, то есть доминирующие в данном обществе мотивы поведения, цели, ценности, их формирование и изменение, то есть то, что принято относить к культуре. Мотивы поведения и стоящие за ними ценности, нормы, представления о должном, оценки и предпочтения - все это относится к сфере «субъективного», оно индивидуально, изменчиво и противоречиво, его сложно исследовать. В качестве примера можно взять широкомасштабное исследование изменения ценностей при переходе к постмодерну, предпринятое Р. Инглхартом и его сотрудниками [2]. На наш взгляд, оно оказалось достаточно поверхностным и декларативным, призванным обосновать идею автора о переходе в современном западном социуме от материальных ценностей к постматериальным.

В основу данного исследования была положена пирамида потребностей Маслоу [3], который опирается, скорее, на здравый смысл, чем на более глубокое исследование мотивации поведения, представленное, например, в работах Франкла [4] и других авторов.

Чтобы преодолеть упрощенный подход в исследовании мотивов поведения, представленный в работах Маслоу и его последователей, мы предлагаем рассмотреть социокультурное пространство современного общества, т.е. общества модерна, пик развития которого приходится, видимо, на середину XX века. Мы попробуем выделить некоторые методологические принципы, на основе которых можно понять происходящие в современном обществе социокультурные процессы, их содержание и направленность.

Необходимость исследования трансформаций ценностных систем. На наш взгляд, важно попытаться понять изменения преобладающих мотивов деятельности индивидов западного общества, выявить основные причины этих изменений и их направленность. 
В настоящее время в социальных науках сложилась базовая схема, применяемая в исследованиях западного социума - движение от премодерна к модерну и постмодерну, исследуются те изменения, которые происходят в западном социуме в настоящее время, такие процессы, как глобализация, Четвертая промышленная революция, цифровизация, системные кризисы, завершение эпохи классического капитализма, «инклюзивный капитализм», зеленая революция и т.д. Все эти исследования важны и необходимы для понимания процессов, которые происходят в современном обществе, однако, на наш взгляд, мы не сможем их понять, если не исследуем важнейшую их составляющую - изменение «субъективной сферы»: ценностей, целей, мотивов деятельности индивидов данного социума. Сфера общественного сознания пока остается малоисследованной, преобладающим стало стремление манипулировать сознанием пользователей сети с целью сбыта определенных товаров и услуг. Навязывание потребностей с помощью рекламы - это нечто конкретное и сиюминутное, но при этом в тени остаются процессы изменения базовых систем ценностей западного социума и базовых мотивов поведения, без понимания которых мы не сможем понять направленность изменений и представить образ ближайшего или отдаленного будущего. Для иллюстрации этого следует вспомнить события нашего недавнего прошлого - крушение социализма и распад СССР, которые стали полной неожиданностью для советской и западной социологии.

На наш взгляд, это произошло потому, что не исследовали изменения, происходящие в сфере «субъективного», мотивов поведения, целей, ценностей, чем удачно воспользовались «реформаторы», разрушившие систему с помощью достаточно небольших, прежде всего информационных, воздействий. Но эти воздействия оказались результативными для тех, кто их осуществлял, в силу того, что на уровне массового сознания уже произошли изменения базовых ценностей и мотивов поведения, которые не исследовались официальной наукой. В конечном счете эти изменения в сфере «субъективного» стали той «бомбой», которая разрушила и социалистическую систему, и страну.
Определенные сдвиги в системе ценностей и мотивов происходят и в современном западном, и российском обществах. Глубинные сдвиги в этой сфере особенно заметны в США, где общество расколото на два лагеря - республиканцев и демократов - именно по ценностному основанию, их видению ближайшего и отдаленного будущего.

Все это свидетельствует о важности исследования «субъективной» сферы социума - господствующих целей, ценностей, мотивов поведения, того, на что впервые обратил внимание М. Вебер и стал активно исследовать в своих работах.

В качестве методологической основы исследования «субъективной» сферы современного общества и его социокультурного пространства в целом мы предлагаем выделить в социокультурном пространстве отдельные подпространства со своими особенными ценностными системами, целями, оценками и мотивами поведения.

Исследования М. Вебера и других социологов и философов показали, что в любом обществе сосуществуют разные, в том числе и противоположные, системы ценностей, которые находятся в сложных отношениях [5]. Общество - совокупность слоев, классов социальных и профессиональных групп, различающихся своей ролью в обществе, образом жизни, интересами, ценностями. Широко известным фактом является, например, различие ценностных ориентаций мужчин и женщин: мужчины активны во внешнем пространстве, они обеспечивают семью, делают карьеру, являются защитниками, воинами и т.д.; женщины активны во внутреннем пространстве семьи, они - «хранительницы очага», жены, матери и т.д.

Различаются также ценности, основные жизненные ориентиры сословий в традиционном обществе: крестьян, рыцарей, духовенства. В рыцарском сословии культивировались такие качества, как честь, верность, воинская доблесть, а также щедрость, расточительность. Эти качества были противоположны качествам, необходимым крестьянскому сословию: трудолюбию, терпению, бережливости и т.д. В современном обществе, или обществе модерна, господствующим становится третье сословие - торговцы, промышленники, банкиры. Соответственно, 
меняется конфигурация социокультурного пространства, в котором происходит рекомбинация ценностей, образуются их новые, ранее не возможные, сочетания, например, богатства и бережливости, что отразилось, как известно, в протестантской этике, выразившей «дух капитализма».

Можно сказать, что в любом обществе постоянно происходит рекомбинация ценностей, одни ценности поднимаются вверх по ценностной шкале, другие опускаются вниз. В Новое время вниз начинают опускаться традиционные христианские ценности: молитва, аскеза, соблюдение заповедей и т.д., а вверх поднимаются ценности, ранее порицаемые: стремление к богатству, власти, удовольствиям.

Разные конфигурации ценностей складываются у разных социальных и профессиональных групп: предпринимателей, военных, врачей, ученых и т.д. У предпринимателей, как известно, главной целью-ценностью является прибыль, в то время как у ученых истина. Противоположны ценности военных и врачей - первые учатся убивать, вторые, наоборот, спасать жизнь.

Можно сказать, что в современном обществе существует множество целей-ценностей, которые образуют определенные устойчивые конфигурации, устойчивые структуры со своим «верхом» и «низом», то есть представлением о достойном и недостойном, хорошем и плохом, правильном и неправильном. Причем, правильное, хорошее и достойное в одной системе ценностей может оказаться неправильным и недостойным в другой. Разные социальные и профессиональные группы имеют разные жизненные ориентиры, ценности, мотивы поведения. Ценностная шкала, принятая в определенном сообществе, представлена в эталоне, образце, который формирует индивида определенного качества, позволяет осуществлять его оценку и сравнение с другими, ранжировать индивидов внутри определенной социальной группы, профессии, выделять среди них лучших, средних и худших. Собственные ценностные шкалы существуют в каждой социальной группе и в каждом профессиональном сообществе: у предпринимателей, врачей, учителей, военных, спортсменов и т.д.

Существующая в социальной группе шкала ценностей, со своим «верхом» и «ни- зом», ориентирует тех, кто входит в данную группу, на движение «вверх», на занятие более высокого положения в социальной иерархии, на соперничество с другими за более высокий статус. Но в любом обществе наряду с множеством профессиональных и групповых систем ценностей формируется общая для всех система ценностей, указывающая наиболее важную, значимую для данного общества цель-ценность, по отношению к которой все остальные - групповые, профессиональные цели-ценности - выступают как средства.

Генезис социокультурного пространства общества модерна. В современном рыночном обществе такой общей для всех единицей измерения ценности каждого, как известно, является доллар, а шкала устроена так, что в ней нет верха, которого можно было бы достичь, всегда есть более высокая ступень, за которой следующая и т.д. Это означает, что в современном рыночном обществе социокультурное пространство утратило жесткие разграничительные линии между отдельными «территориями», в качестве которых выступают отдельные сословия, социальные и профессиональные группы. Границы стали более открытыми, проницаемыми. В эпоху становления современного общества возросшая вертикальная мобильность индивидов привела к тому, что ценности «верха», то есть господствующего аристократического слоя, и «низа» - низших слоев, стали смешиваться, образуя новые конфигурации. Ценности «верха» стали просачиваться «вниз», а ценности «низа» стали подниматься «наверх», порождая, например, то, что М. Вебер и В. Зомбарт назвали «духом капитализма», воплощением которого стал современный предприниматель.

В. Зомбарт отмечает, что одной из главных составляющих «капиталистического духа» является жажда наживы. Он писал, что «в первые десятилетия XVII столетия французское и английское общества пережили то первое болезненное состояние денежной горячки, ... которым так глубоко проникся весь организм народа, что теперь всеобщая страсть к деньгам может рассматриваться как основное свойство души современного человека» $[6$, с. 26$]$. 
Предпринимательская энергия, по мнению В. Зомбарта, в своей основе имеет стремление к наживе, которое способно преодолеть любые моральные ограничения. Он отмечает: «К великим победителям на ристалище современного капитализма имеет, пожалуй, общее применение то, что еще недавно сказали о Рокфеллере, что он "умел с почти наивным отсутствием способности с чем бы то ни было считаться, перескочить через всякую моральную преграду"» [6, с. 26].

Следующая составляющая «капиталистического духа» - это «мещанские добродетели»: трудолюбие, экономия, бережливость, которые появились на свет в ремесленных каморках, в условиях нужды. «Здесь нужно было быть бережливым, и трезвым, и трудолюбивым, и целомудренным, если не желать ставить на карту своего существования» [6, с. 26].

Тип личности предпринимателя В. Зомбарт определяет как «экономический человек». Он считал, что современный экономический человек «в наиболее чистом виде проявляется в американском предпринимателе». В. Зомбарт и М. Вебер показывают, что мотивация предпринимателя формируется в результате переформатирования системы ценностей «третьего сословия», соединения жажды наживы, расчетливости, трудолюбия, которые сочетались с пренебрежением к прежним моральным ограничениям.

Ценности «верха» и «низа» в эпоху становления рыночного общества стали смешиваться также благодаря развитию системы образования. В школах детей низших слоев учили правильно вести себя, правильно говорить, управлять своими эмоциями, что было свойственно представителям высшего слоя. Дети более высоких слоев в школах общались с детьми низших, что также могло трансформировать их систему ценностей. Тем самым социокультурное пространство современного общества демократизировалось, ценности перестали быть жестко связанными с определенным социальным слоем или социальной группой. Они стали перемешиваться, образовывать новые устойчивые сочетания.

Можно сказать, что социокультурное пространство современного рыночного общества формировалось в результате взаимодействия различных социальных слоев - «верха», «среднего слоя» и «низа», что привело к сосуществованию и взаимодополнению в нем таких высших, можно сказать, христианских ценностей, как свобода, равенство, братство, и ценностей низших, эгоистических: «каждый сам за себя» и «человек человеку - волк». Это наглядно выражено в известной повести Дж. Лондона «Морской волк». Уже в ее начале упоминаются имена Шопенгауэра и Ницше, идеи которых отразили появление нового качества социокультурного пространства общества модерна - его освобождение от Бога, то есть от христианской системы ценностей. «Смерть Бога» является, по Ницше, постулатом колоссальной важности, прежде всего, для европейской культуры, но в перспективе - и для всего человечества. Ницше не призывает к «убийству Бога», и не совершает это убийство - он констатирует свершившийся факт. «Смерть Бога» рассматривается Ницше как свершившийся феномен и как ключевое событие европейской культуры. Оно, с одной стороны, является закономерным следствием ее развития и, с другой стороны - и это главное, мощным фактором, предопределяющим ее кризис и дальнейшее развитие [7, с. 171].

Ницше провозгласил «смерть Бога», христианской морали и выдвинул идею «сверхчеловека», который сам создает свои ценности. Это означает, что теперь западный индивид освобождается от прежней христианской морали и сам решает, что для него добро, а что зло.

В повести «Морской волк» сталкиваются главные герои: капитан Ларсен, уверенный, что человек - это хитрое, подлое и злое существо, и безраздельно подчинивший себе экипаж шхуны, и рафинированный интеллигент, филолог Хэмфри Ван-Вейден, отстаивающий иное, христианское, отношение к человеку.

Это означает, что в обществе модерна в период становления сосуществовали и взаимодействовали между собой два уровня культуры: высший уровень, который был представлен образованным слоем, «теоретиками», теми, кто создавал и распространял новые идеи («свобода», «равенство», «права человека» и т.д.), и массовый уровень «практиков», тех, кто воплощал эти идеи в жизнь - торговцев, промышленников, банкиров, наемных работников и т.д. Естественно, что на уровне «практиков», осуществляв- 
ших процесс экономической и социальной модернизации общества, на уровне реальной жизни, идеи свободы и равенства получали иное - рыночное - наполнение: как освобождение от прежних религиозных и моральных ограничений в конкурентной борьбе за прибыль.

Результаты социокультурной модернизации. Снятие прежних сословных ограничений, провозглашенное идеологами модерна, в реальности обернулось не созданием нового свободного и процветающего общества, а общества с глубоким социальным неравенством, в котором жадность, зависть, честолюбие и эгоизм перестали быть пороками и рассматривались как естественные проявления человеческой природы. «Буржуазный век принес свободу, — писал Э. Фукс, — люди были убеждены, что это золотой век. Осуществлен истинно нравственный миропорядок. Отныне есть только люди. Нет больше деления на господ и рабов, на поработителей и порабощенных. Есть только свободные от рождения граждане. Воцарятся добродетели. Точно мрачные тени ночи, исчезнут пороки. Рассеются, как дым, нужда, заботы, страх и отчаяние. По стране пройдет богиня богатства, расточая без устали всем и каждому свое благословение. Только во имя великих идеалов будут лихорадочно работать мозги людей. Свобода, братство и равенство будут служить связующим звеном не только между отдельными гражданами в каждой стране, но и между всеми странами земного шара» [8, с. 22]. Однако эти надежды не оправдались.

«Посмотрим, - писал Э. Фукс, - что сделало богатство из отдельных его представителей? Вознесло ли оно их в духовном, душевном и моральном отношении над их прежним уровнем? Пробудило ли оно в них высшие добродетели? Создало ли оно поколение героев? Нет, произошло как раз обратное. Отвратительные денежные машины, лишенные всякого чувства, всякой чуткости, вот что сделал прежде всего капитал из тех, кто им владел и кто им командовал» [8, с. 22].

Очевидно, что произошедшая в XVIIIXIX веках, в эпоху становления общества модерна, трансформация традиционной системы ценностей, в результате которой наверх поднялись ценности индивидуализма и эго- изма, стала прологом двух мировых войн и гибели десятков миллионов людей. Однако идеологи Запада не смогли сделать из этого правильные выводы и попытаться изменить жизненные ориентиры западного человека с целью умерить его индивидуализм, эгоизм и стремление к наживе.

Опираясь на исследования американских социологов, Ф. Фукуяма в своей работе «Великий разрыв», проанализировав данные о преступности, состоянии семьи (включая рождаемость, браки, разводы), уровне доверия, вынужден был констатировать нарастание индивидуализма и эгоизма в американском обществе, снижение уровне доверия, рост отчужденности и т.д. Ф. Фукуяма отмечает, что «между 50-ми и 90-ми годами в США и других западных странах произошли огромные перемены в ценностях. Эти перемены в нормах и ценностях сложны, но могут быть подведены под общую рубрику возрастающего индивидуализма. В современных обществах степень свободы выбора для индивидов чрезвычайно возросла, в то время как узы, связывающие их с системой социальных обязательств, заметно ослабли» $[9$, с. 89].

Ф. Фукуяма считает, что «общих ценностей, которые бы разделялись членами общества, стало меньше, а соперничества среди групп - больше» [9, с. 89]. По его мнению, доверие подрывается чрезмерным эгоизмом.

Общий вывод автора: «Великий Разрыв характеризуется растущим уровнем преступности и социальной дезорганизации, упадком семьи и родственных отношений как источников социальной сплоченности и снижающимся уровнем доверия. Начиная с 60-х годов все эти изменения стали происходить в большинстве развитых стран и протекали очень быстро по сравнению с изменениями общественных норм, происходившими в более ранние периоды» [9, с. 90].

Переход в постмодерн. Во второй половине XX века западный социум перешел в состояние постмодерна. В философии, социологии и политологии до сих пор не утихают дискуссии о том, что такое постмодерн и как к нему относиться. Был даже такой казус, когда в 90-е годы ельцинский министр МВД Д. Куликов заявил, что во всех бедах России виноват постмодерн. 
И. М. Семашко считает, что в понимании постмодерна можно выделить следующие позиции: «первая позиция утверждает, что постмодерн - это определенная, исторически обусловленная мутация самого модерна: “проект Просвещения" оказался в ситуации внутреннего и внешнего кризиса, и требует качественной трансформации, адаптации к новым условиям, пусть даже созданным им же самим. Вторая позиция утверждает, что постмодерн - это уже не-модерн, это именно отрицание модерна, которое начинается с критики его тоталитарной категоричности, а закончится восстанием против его сущностных основ - самого секулярного проекта. Наконец, третья позиция утверждает, что постмодерн - это автономная, самозамкнутая историческая парадигма, являющая собой абсолютно новый, “третий путь”, равно альтернативный как традиции, так и модерну» [10, с. 59].

Сейчас о постмодерне говорить стали меньше, мы просто в нем живем. Основные признаки состояния постмодерна - деконструкция основ прежней классической культуры, сложившейся в эпоху модерна, тотальный релятивизм, иррационализм, освобождение от всех прежних ограничений, переход в состояние постправды, симуляция, распространившаяся во всех сферах нашей жизни - политике, экономике, образовании, здравоохранении и т.д., гипертрофированное внимание к защите прав меньшинств и реальное ограничение гражданских прав, рост насилия, фальсификация выборов и т.д.

Все это свидетельствует о том, что социокультурное пространство современного общества стремительно меняется. В нем утрачивают свое значение прежние идеологические системы: либерализм, консерватизм, марксизм, социалдемократия и т.д., вокруг которых образовывались политические партии, происходили выборы, строилась внутренняя и внешняя политика. Социокультурное пространство современного общества перестает быть пространством взаимодействия различных систем ценностей, принадлежащих различным слоям, социальным и профессиональным группам, которые благодаря этому взаимодействию уравновешивали друг друга. Оно становится ценностно однородным, в нем ценности заменены ценой. Сей- час все имеет свою цену: кресло министpa, депутата, судьи, мэра и т.д., на нижнем уровне свою цену имеет лечение, обучение, диплом, справка, решение и т.п. Это означает, что в обществе перестает быть значимым и важным все, что выходит за рамки личного интереса. Общество превращается в поле столкновения отдельных частных или групповых интересов, где побеждает тот, у кого больше ресурсов. В этой ситуации нарастают деструктивные процессы, происходит атомизация индивидов, разрушение всех устойчивых связей - семейных, дружеских, профессиональных и т.д.

Заключение. Все сказанное позволяет сформулировать ряд основных положений, на которые следует опираться в исследованиях социокультурного пространства современного общества.

1. Мы не сможем понять современное общество, происходящие в нем изменения и тенденции развития, если не исследуем ценности, цели, мотивы поведения действующих в нем индивидов.

2. Бесконечное разнообразие мотивов и целей отдельных индивидов может быть сведено к нескольким основным, сформированным в современном обществе «идеальным типам» (по терминологии М. Вебера), в которых представлены типичные мотивы поведения, цели-ценности основных социальных групп, таких как бизнесмены, военные, учителя, врачи, ученые и т.д.

3. В период становления и развития общества модерна представленные в нем основные социальные группы были относительно автономны, в каждой из них существовала собственная система ценностей, шкала оценок, мотивация поведения. Они активно взаимодействовали, влияли друг на друга, что приводило к диффузии ценностей, трансформации ценностных систем «верха» и «низа», их уравновешиванию. Особенно активно это происходило в Западной Европе и США.

4. Изменения социокультурного пространства общества модерна в целом привели к «переворачиванию» прежней христианской системы ценностей: то, что в прежней культуре было «верхом», идеалом, ценным, значимым, в культуре общества модерна становится «низом», а то, что было «низом», 
греховным, порицаемым, становится «верхом». Традиционная аскетическая христианская культура, ориентировавшая человека на очищение души, освобождение от пороков, сменилась на индивидуалистическую, гедонистическую культуру, в которой эгоизм, честолюбие, алчность, переименованная в «максимизацию прибыли», становятся основными добродетелями.

5. Выход из кризиса, в который все глубже погружается современное общество, предполагает, кроме всего прочего, радикальное изменение его ценностно-нормативной системы, изменение важнейших жизненных ориентиров, то есть работы с сознанием, движения к все большей осознанности в поведении каждого.

\section{Список источников}

1. Вебер М. Протестантская этика и дух капитализма. М.: Прогресс, 1990. 808 с.

2. Инглхарт Р.Ф. Культурный сдвиг в зрелом индустриальном обществе // Новая постиндустриальная волна на Западе. Антология. М.: Academia, 1999. 631 c.

3. Маслоу А. Психология бытия. М.: Рефл-бук, 1997. 270 с.

4. Франкл В. Человек в поисках смысла. М.: Прогресс, 1990. 368 с.

5. Арон Р. Этапы развития социальной мысли. М.: Прогресс - Политика, 1993. C. 511-514.

6. Зомбарт В. Буржуа / Институт социологии. М.: Наука, 1997. С. 26.

7. Любченко В.С. Человек в обществе Модерна. Новочеркасск: ЛИК, 2013. 298 с.

8. Фукс Э. Иллюстрированная история нравов. Т. 3. Буржуазный век. М.: Республика, 1994. С. 22.

9. Фукуяма Ф. Великий разрыв. М.: ООО «Изд-во АСТ», 2003. С. 89-90.

10. Семашко И.М. «Модерн» / «Постмодерн»: история контроверзы в работах Ю. Хабермаса и Ж. Лиотара // Вестник Вол-
ГУ. Серия 9. Общественные науки. 2010. Вып. 8. Ч. 1. С. 59.

\section{References}

1. Veber M. Protestantskaja jetika i duh kapitalizma [Protestant ethics and the spirit of capitalism]. Moscow: Progress, 1990. 808 p. (In Russ.).

2. Inglhart R.F. Kul'turnyj sdvig $\mathrm{v}$ zrelom industrial'nom obshhestve [Cultural shift in mature industrial society]. Novaja postindustrial'naja volna na Zapade. Antologija [New post-industrial wave in the West. Anthology]. Moscow: Academia, 1999. 631 p. (In Russ.).

3. Maslou A. Psihologija bytija [Psychology of being]. Moscow: Refl-buk, 1997. 270 p. (In Russ.).

4. Frankl V. Chelovek v poiskah smysla [Man in search of meaning]. Moscow: Progress, 1990. 368 p. (In Russ.).

5. Aron R. Jetapy razvitija social'noj mysli [Stages of the development of social thought]. Moscow: Progress — Politika, 1993. P. 511514. (In Russ.).

6. Zombart V. Burzhua [Bourgeois].Institut sociologii [Institute of Sociology]. Moscow: Nauka, 1997. P. 26. (In Russ.).

7. Ljubchenko V.S. Chelovek v obshhestve Moderna [Man in Modern Society]. Novocherkassk: LIK, 2013. 298 p. (In Russ.).

8. Fuks Je. Illjustrirovannaja istorija nravov. T. 3. Burzhuaznyj vek [Illustrated history of morals. Vol. 3. The Bourgeois century]. Moscow: Respublika, 1994. P. 22. (In Russ.).

9. Fukujama F. Velikij razryv [The Great Gap]. Moscow: OOO «Izd-vo AST», 2003. P. 89-90. (In Russ.).

10. Semashko I. M. «Modern». «Postmodern»: istorija kontroverzy v rabotah $\mathrm{Ju}$. Habermasa i Zh. Liotara [«Postmodern»: the history of counter-examination in the works of Y. Habermas and J. Liotar]. Vestnik VolGU. Serija 9. Obshhestvennye nauki [Bulletin of the Volgograd State University. Series 9. Social Sciences]. 2010; 8. P. 1: 59. (In Russ.).

Статья поступила в редакиию 10.12.2021; одобрена после рецензирования 12.12.2021; принята к публикации 18.12.2021.

The article was submitted on 10.12.2021; approved after reviewing on 12.12.2021; accepted for publication on 18.12.2021. 


\section{ИНФОРМАЦИЯ ОБ АВТОРАХ}

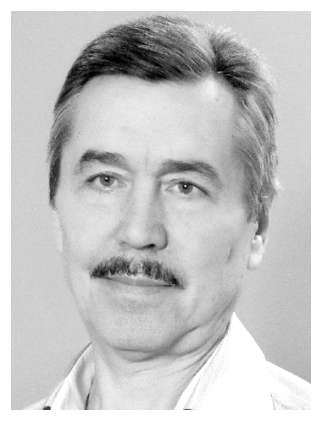

Любченко Василий Сергеевич - доктор философских наук, профессор кафедры «Социальные и гуманитарные науки» Южно-Российского государственного политехнического университета (НПИ) им. М. И. Платова.

Россия, г. Новочеркасск, ул. Просвещения, 132

Vasiliy S. Lyubchenko - Doctor of Philosophical Sciences, Professor, «Social Sciences and Humanities» Department, Platov South Russian State Polytechnic University (NPI).

132 Prosveshcheniya st., Novocherkassk, Russia 